\title{
Perventricular device closure of perimembranous ventricular septal defects in 61 young children: Early and midterm follow-up results
}

\author{
Kaiyu Tao, MD, ${ }^{a}$ Ke Lin, MD, ${ }^{\mathrm{a}}$ Yingkang Shi, MD, ${ }^{\mathrm{a}}$ Haibo Song, MD, ${ }^{\mathrm{b}}$ Raphael C. Lui, MD, FACS, ${ }^{\mathrm{a}}$ \\ Changping Gan, MD, ${ }^{\mathrm{a}}$ and Qi An, MD ${ }^{\mathrm{a}}$
}

\begin{abstract}
Objectives: Perventricular device closure of perimembranous ventricular septal defect as a novel technique has recently been described in several small series with initial experience. Further studies with larger cohorts and longer-term follow-up are needed to confirm the validity of this new approach. This report describes our recent experience with perventricular device closure of perimembranous ventricular septal defects on beating hearts in 61 young children with over 1 year of follow-up.
\end{abstract}

\begin{abstract}
Methods: Between April 2007 and April 2008, 61 patients with perimembranous ventricular septal defects were enrolled for a prospective study of perventricular device closure of their defects. The hospital course and the immediate and midterm complications during follow-up were herein reported.
\end{abstract}

Results: The defects were closed successfully with devices in $57(93.4 \%)$ patients without mortality or major morbidity. Four $(6.6 \%)$ patients were converted to surgical repair when device closure was deemed unsuccessful; the failure of device closure was associated with the subaortic rim (odds ratio $=21.471 ; P=.038$ ). Residual shunt was observed in $4(6.6 \%)$ patients during the procedure. One of them was converted into surgical repair, and the residual shunt of the other 3 resolved during the 6-month follow-up period. Two (3.3\%) patients had complete atrioventricular block develop in the operating room or during follow-up. One was converted into surgical repair and the other patient converted to sinus rhythm after treatment with steroids.

Conclusions: Perventricular device closure of ventricular septal defect is a safe and efficacious treatment option with acceptable midterm outcomes. For infants with poor vascular access, it might be the procedure of choice.

(J Thorac Cardiovasc Surg 2010;140:864-70)

Perimembranous ventricular septal defect (VSD) is the most common congenital cardiac malformation. Surgical repair of VSD with cardiopulmonary bypass (CPB) has been the conventional treatment modality for the past several decades. With better understanding of the pathophysiology of complications associated with $\mathrm{CPB}$ and the improvements in $\mathrm{CPB}$ technique, $\mathrm{CPB}$ is much safer in infants ${ }^{1}$; however, the post-CPB neurologic outcomes, which would affect the quality of life, need to be improved..$^{2-4}$ The intangible psychologic impact of a long chest scar on a young girl has yet defied any evaluation. Another therapeutic approach, namely interventional transcatheter device closure, is much less invasive with encouraging outcomes, ${ }^{5,6}$ but this

From the Departments of Thoracic and Cardiovascular Surgery a and Anesthesiology, West China Hospital, Sichuan University, Sichuan, People's Republic of China.

Funded by The Ministry of Science and Technology of the People's Republic of China (2006BAI01A08).

Disclosures: None.

Clinical Trial Registration Information: http://www.chictr.org.

Unique Identifier: ChiCTR-TNC-00000203.

K.T. and K.L. contributed equally to this article.

Received for publication Sept 21, 2009; revisions received April 27, 2010; accepted for publication May 16, 2010; available ahead of print June 21, 2010.

Address for reprints: Qi An, MD, Department of Thoracic and Cardiovascular Surgery,

West China Hospital, Chengdu, Sichuan, People's Republic of China 610041

(E-mail: anqi8890@163.com).

$0022-5223 / \$ 36.00$

Copyright (c) 2010 by The American Association for Thoracic Surgery doi:10.1016/j.jtcvs.2010.05.013 approach can be very challenging technically in infants and has limitations and potential long-term complications such as rhythm disturbances and hemodynamic compromise of the lower limbs owing to the small size of access vessels. The long-term sequel of prolonged fluoroscopic exposure on various organs is still not fully understood. More recently, the initial experience of perventricular device closure of VSD without CPB and prolonged irradiation from fluoroscopy has been described in several small series with encouraging outcomes. ${ }^{7-12}$ The risks of potential late complications of this novel approach, such as complete atrioventricular block (cAVB) ${ }^{13}$ however, has not been addressed by these reports. This report describes our experience with perventricular device closure of VSD on beating hearts in 61 infants and young children with midterm follow-up.

\section{METHODS}

The study was approved by The Chinese Clinical Trial Register and West China Hospital Ethics Committee.

\section{Patients}

Between April, 2007 and April, 2008, 435 patients with VSD were referred to our department for closure of VSD. Sixty-one of them were enrolled in this study according to their transthoracic echocardiography results performed with a Philips Sonos 5500 echocardiograph (Philips, Amsterdam, the Netherlands). Inclusion criteria to the study are (1) younger than 3 years of age or body weight less than $15 \mathrm{~kg}$; (2) evidence of uncontrolled congestive heart failure or recurrent pneumonitis requiring early 


$$
\begin{aligned}
& \text { Abbreviations and Acronyms } \\
& \begin{aligned}
\text { AR } & =\text { aortic regurgitation } \\
\text { cAVB } & =\text { complete atrioventricular block } \\
\text { CI } & =\text { confidence interval } \\
\text { CPB } & =\text { cardiopulmonary bypass } \\
\text { IRBBB } & =\text { incomplete right bundle branch block } \\
\text { LV } & =\text { left ventricle (ventricular) } \\
\text { OR } & =\text { odds ratio } \\
\text { RV } & =\text { right ventricle (ventricular) } \\
\text { TEE } & =\text { transesophageal echocardiography } \\
\text { VSD } & =\text { ventricular septal defect }
\end{aligned}
\end{aligned}
$$

intervention; and (3) family consent to device closure. Exclusion criteria are (1) prolapse of the aortic valve noncoronary leaflet or (2) cardiac arrhythmia. The option of perventricular device closure of VSD was thoroughly discussed with patients or legal guardians, and specific informed consent was obtained. The pulmonary/systemic flow ratios were not available for any of these patients inasmuch as no-one in the series required cardiac catheterization. The general characteristics of enrolled patients are summarized in Table 1.

\section{Devices}

The device used for the study is composed of a VSD occluder (SQFDQII) and its delivery system ${ }^{9,11}$ (Shanghai Shape Memory Alloy Co, Ltd [SHSMA], Shanghai, China). The self-expandable occluder is made of 0.004-inch nitinol wires woven to form 2 discs with a short connecting waist, and Dacron is sewn inside each disc to prevent left-to-right shunt. Two different kinds of occluders were used: one is the concentric type (Figure 1,E) and the other is the eccentric type (Figure 1,D). The flanges of the 2 ventricular discs in the concentric type are $2-\mathrm{mm}$ wide. The right ventricular (RV) disc of the eccentric type is the same as that of the concentric type, but the flange of the left ventricular (LV) disc facing the aortic valve is only $0.5-\mathrm{mm}$ wide or absent so as to prevent impingement of the aortic valve, and the opposite flange at the same disk is 5-mm long and has a metallic mark on its edge to indicate the orientation under transesophageal echocardiography (TEE).

A female screw is welded in the center of the RV disc to which the delivery cable can be attached.

\section{Perventricular Device Closure Technique}

The free wall of the RV was exposed by a lower partial median sternotomy (Figure 2, A), and systemic heparinization was achieved by giving 1 $\mathrm{mg} / \mathrm{kg}$ body weight of heparin sodium intravenously. TEE (Philips Sonos 4500) was performed to confirm the location and diameter of the defect. An occluder was chosen according to the location and diameter of the defect by the consensus of the surgeon and the cardiac sonographer.

The occluder was attached to the delivery cable and a 4-0 Prolene polypropylene suture (Ethicon, Inc, Somerville,NJ) was passed through the base of the RV disc of the occluder, with which the device could be retrieved after release if needed. Then the occluder was pulled into a loader sheath (Figure 1, A) along with the 4-0 Prolene polypropylene suture.

Under the continuous guidance of TEE, the surgeon gently depressed the $\mathrm{RV}$ free wall with his index finger. The indentation of the RV cavity could be easily seen by TEE. A puncture site on the RV free wall was finally selected. The site was closest to the defect, and yet an imaginary line drawn between this point and the defect was perpendicular or nearly so to the plane of the ventricular septum. A pledget-supported 4-0 Prolene polypropylene purse-string suture was placed around the chosen puncture site, and a 20-gauge needle was inserted all the way into the RV cavity under TEE guidance. A flexible 0.035 -inch guide wire was introduced into the RV through the needle and was maneuvered into the LV through the defect. The needle was then removed (Figure 2, B). A double-layer delivery sheath was advanced into the LV over the guide wire, and then the inner layer sheath (Figure 1,C) and the guide wire were removed together (Figure 2, $E$ ), leaving the outer delivery sheath (Figure $1, B$ ) in position to guide further delivery. During the procedure, the purse-string suture was tightened to prevent excessive blood loss. However, a considerable amount of blood from the LV was allowed to flood the delivery sheath so as to avoid air being pushed into the LV during subsequent maneuvers. The previously prepared loader sheath, which contained the occluder, was connected to the free end of the delivery sheath (Figure 1,B) to load the occluder into the delivery sheath. Under the guidance of TEE, the LV disc was deployed first by pushing the cable forward while holding the delivery sheath still. Once the expanded LV disc was visualized by TEE, the cable and the delivery sheath together were gently pulled back until the underside of the LV disc was pulled up snugly against the left side of the ventricular septum. The waist and the RV disc were now deployed by pulling back the delivery sheath while holding the cable still until expansion of the RV disc was fully visualized by TEE (Figure 2, $C$ ). Residual shunt and device-induced new regurgitation of the mitral or tricuspid valve were looked for by multiplane TEE. If no complications was found, the loader sheath and the carrier cable were withdrawn simultaneously, and the occluder was released by counterclockwise rotation of the cable after its position and stability were confirmed (Figure 2,F). The Prolene polypropylene suture that served to retrieve the occluder in case its placement was unsatisfying during the postprocedural observation period was cut and removed. The purse-string suture on the $\mathrm{RV}$ free wall was tied.

All the patients received aspirin $\left(3 \mathrm{mg} \cdot \mathrm{kg}^{-1} \cdot \mathrm{d}^{-1}\right)$ by mouth for 6 months starting on the first postoperative day.

\section{Follow-up}

Standard 12-lead electrocardiogram, chest radiograph, and transthoracic echocardiography were performed routinely on postoperative day 2 or 3 , before discharge, and at 6 and 12 months during follow-up. Twenty-four-hour electrocardiographic Holter monitoring was performed if needed. The importance of timely follow-ups was explained and emphasized to all the patients and guardians.

\section{Statistics}

Data are expressed as percentage for nominal variables and mean $\pm \mathrm{SD}$ (range) for continuous variables. The SPSS 16.0 for windows (SPSS Inc, Chicago, Ill) was used for statistical analysis.

Residual shunt, cAVB, aortic regurgitation (AR), tricuspid regurgitation, mitral regurgitation, incomplete right bundle branch block (IRBBB), and failure of device closure were analyzed as dependent outcome variables. Gender, age, weight, mean VSD diameter, device diameter, subaortic rim ( $\leq 2 \mathrm{~mm}$ or $>2 \mathrm{~mm}$ ), ratio of device diameter to VSD diameter, ratio of VSD diameter to patient weight, and ratio of device diameter to patient weight were analyzed as independent variables.

Univariate analysis was performed by the Student $t$ test and $\chi^{2}$ test or Fisher's exact test. Multiple logistic regression analysis was performed to study risk factors for the occurrence of early complications and failed procedure. "Early complications" were defined as occurring during the hospitalization. Independent variables with a $P$ value less than .2 in the univariate analysis were included in the multivariable analysis; odds ratio (OR) and its $95 \%$ confidence intervals $(\mathrm{CI})$ were calculated.

\section{RESULTS}

\section{Procedural Data}

Sixty-one patients were enrolled in the study, and in 57 $(93.4 \%)$ of them the defects were successfully closed 
TABLE 1. General characteristics of 61 patients

\begin{tabular}{lc}
\hline \multicolumn{1}{c}{ Gender (female/male) } & $\mathbf{3 4 / 2 7}$ \\
\hline Mean age and age range $(\mathrm{mo})$ & $34.4 \pm 14.5($ range, $7-60)$ \\
Mean weight and weight range $(\mathrm{kg})$ & $12.6 \pm 3.2($ range, $6-24)$ \\
VSD diameter $(\mathrm{mm})$ & $5.3 \pm 1.6($ range, $3.5-11)$ \\
Subaortic rim & \\
$\leq 2 \mathrm{~mm}$ & 16 patients $(26.2 \%)$ \\
$\leq 1 \mathrm{~mm}$ & 6 patients $(9.8 \%)$ \\
$>2 \mathrm{~mm}$ & 45 patients $(73.8 \%)$ \\
Preoperative valvular regurgitation & \\
Tricuspid regurgitation & 15 patients $(24.6 \%)$ \\
Mitral regurgitation & 3 patients $(4.9 \%)$ \\
Presence of an aneurysm & 11 patients $(18.0 \%)$ \\
\hline$V S D$, Ventricular septal defect. &
\end{tabular}

perventricularly. Follow-up data were obtained from 56 patients over 1 year; lost to follow-up rate was $8.2 \%$. The median follow-up was 22 months (range, 16-28 months). There was no mortality during either hospital stay or the entire follow-up period. Data are summarized in Table 2. Four $(6.6 \%)$ patients were converted to conventional surgical repair with CPB. Mild AR developed immediately after the deployment of an eccentric occluder in $2(3.3 \%)$ children; the subaortic rim of the defect was $1 \mathrm{~mm}$ in 1 patient, and less than $1 \mathrm{~mm}$ in the other. They were converted to conventional surgical repair after failure to eliminate the AR by adjusting the direction of the LV disc. No AR was detected by TEE after surgical closure. Residual shunt $(>2-\mathrm{mm}$ color jet width) was noticed in 1 boy with a subaortic rim less than $2 \mathrm{~mm}$. The original concentric device was then exchanged for a bigger eccentric device, but the residual shunt remained; therefore, the patient was converted to conventional surgical repair and no residual shunt was detected after surgery. cAVB occurred 5 minutes after deployment of a concentric device in 1 patient. The device was retrieved and the patient was converted to conventional surgical repair and treated with dexamethasone. Postoperatively, this patient had 2:1 conduction block. Dexamethasone was continued for 1 week when the rhythm converted to sinus rhythm. During the follow-up, the patient remained in sinus rhythm. The information on 4 patients is summarized in Table 3 .

Univariate analysis showed that failure of device closure was associated with VSD diameter $(P=.020)$ but not associated with device diameter $(P=.070)$, subaortic rim $(P=.052)$, or other independent variables. However, multiple logistic regression analysis was performed that showed that only the subaortic rim was associated with the failure of device closure (OR, 21.471; 95\% CI, 1.188-387.929; $P=.038)$.

\section{Arrhythmic Complications}

One cAVB occurred in the operating room, as mentioned earlier. No cAVB was noticed within 6 months after the procedures in the patients who underwent successful closure with the device. However, cAVB developed 7 months after

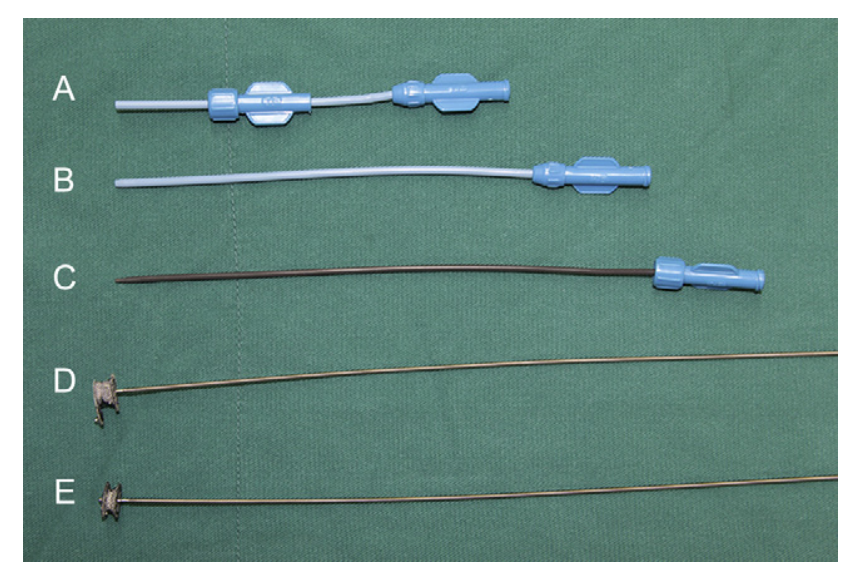

FIGURE 1. Ventricular septal defect occluders and delivery systems. A, A loader sheath. B, A delivery sheath. C, An inner layer sheath. D, An eccentric device with no flange of the left ventricular disc facing the aortic valve; the opposite flange at the same disc is 5-mm long and has a metallic mark on its edge to indicate the orientation under transesophageal echocardiography. E, A concentric device with 2-mm flanges of 2 ventricular discs.

the procedure in 1 patient. This 3-year-old boy, who had a 7 $\mathrm{mm}$ perimembranous VSD closed with a 9-mm concentric occluder, was discharged with device-related IRBBB. He returned to the hospital 7 months later with low heart rate. A 12-lead electrocardiogram confirmed cAVB, with an ideoventricular rate of 47 beats $/ \mathrm{min}$. The patient was completely free of symptoms and was initially treated with dexamethasone $\left(1.5 \mathrm{mg} \cdot \mathrm{kg}^{-1} \cdot \mathrm{d}^{-1}\right)$ orally for 1 week when atrioventricular conduction was re-established. Dexamethasone was decreased to $1 \mathrm{mg} \cdot \mathrm{kg}^{-1} \cdot \mathrm{d}^{-1}$ in the second week and $0.5 \mathrm{mg}$ $\cdot \mathrm{kg}^{-1} \cdot \mathrm{d}^{-1}$ in the third and fourth weeks, after which it was discontinued. The patient remained in stable sinus rhythm with IRBBB 14 months after recovery from cAVB.

IRBBB developed in $5(8.2 \%)$ patients in the operating room. It disappeared in 2 of the patients before discharge after the administration of dexamethasone, but it persisted and remained stable in the other 3 patients during follow-up.

No risk factor was found related to arrhythmic complications.

\section{Residual Shunts and Device Embolization}

Residual shunt was observed in $4(6.6 \%)$ patients; one of them was converted to surgical repair as mentioned earlier. Residual shunts in the other 3 patients resolved spontaneously within 6 months after the procedures. No risk factor was found related to residual shunt. No device embolization was observed in the operating room or during the follow-up period.

\section{Valvular Regurgitation}

AR occurred in $2(3.3 \%)$ patients as mentioned earlier. No device-related AR was noticed in the 57 patients whose VSDs were successfully closed with devices. All pre-existing 


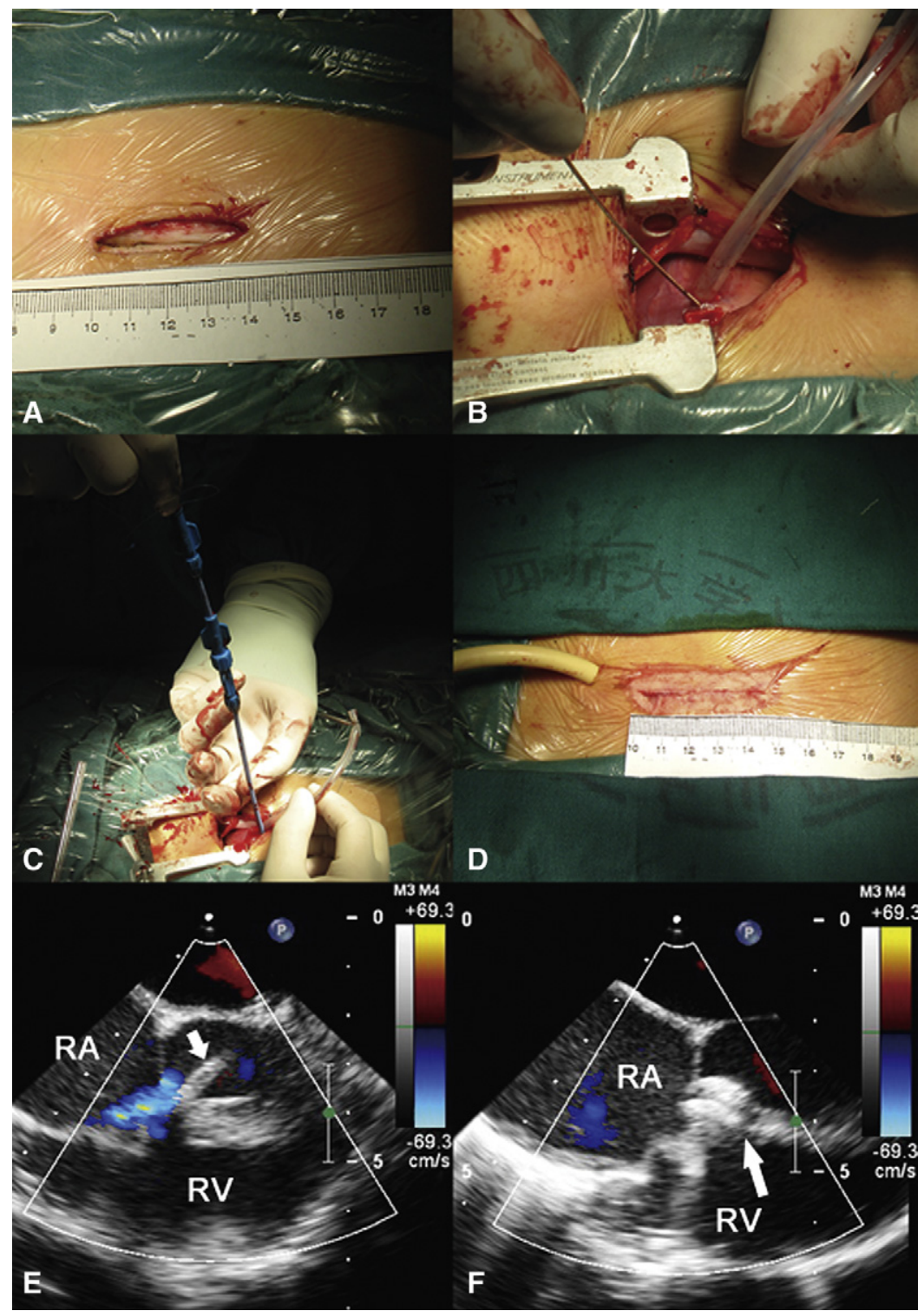

FIGURE 2. Series of intraoperative photographs of device closure procedure and transesophageal echocardiographic images. A, The inferior partial sternotomy was $4 \mathrm{~cm}$ in length. B, The guide wire was introduced via the puncture site on the right ventricular free wall. C, The device was deployed. D, A pericardial drainage tube was placed, and the incision was sutured. E, Preclosure transesophageal echocardiogram showing the delivery sheath (arrow) passing through the ventricular septal defect. F, Postclosure transesophageal echocardiographic image. The ventricular septal defect was closed with a device (arrow). RA, Right atrium; $R V$, right ventricle.

tricuspid regurgitations diminished immediately after the procedure and 4 of them disappeared entirely in the operating room. Six of them persisted during the follow-up. However, new tricuspid regurgitation was observed in $8(13.1 \%)$ patients in the operating room but all were graded as trivial and 3 of them resolved before discharge. Mitral regurgitation was noticed in 3 patients before device closure; in 2 of them the mitral regurgitation disappeared in the operating room and in the third it remained the same during follow-up.

The occurrence of valvular regurgitation was not related to any of the independent variables analyzed.

\section{Hospital Stay and Other Issues}

Fifty-one $(89.5 \%$ ) patients with device closures were extubated in the operating room. None of the patients required blood transfusion during hospitalization. The mean postoperative hospital stay was $5.3 \pm 1.3$ days (range, $2-9$ days). All the complications are summarized in Table 4.

\section{DISCUSSION}

Successful perventricular device closure of VSD was first reported by Amin and associates ${ }^{8}$ in 1998. Subsequently Okubo, ${ }^{14}$ Bacha, ${ }^{7}$ Zeng, ${ }^{9} \mathrm{Li},{ }^{10}$ Gan, ${ }^{11}$ Quansheng, ${ }^{12}$ and 
TABLE 2. Procedural data

\begin{tabular}{ll}
\hline Procedure time (min) & $90.3 \pm 20.2$ (range, $45-140)$ \\
Mean size of the device used $(\mathrm{mm})$ & $7.3 \pm 2.0$ (range, 4-12) \\
Device diameter/VSD diameter* $(\%)$ & $142 \pm 18$ (range, 109-200) \\
$\begin{array}{l}\text { Device diameter/weight }(\%) \\
\text { Type of device used }\end{array}$ & $63 \pm 30$ (range, 25-182) \\
Concentric type & 46 patients \\
Eccentric type & 15 patients \\
\hline
\end{tabular}

*Mean diameter of 1 defect.

their coworkers also reported their initial experiences with perventricular device closure of VSD. However, these studies all suffered from the shortcoming of having a small number of patients and short follow-ups; therefore, the midterm and long-term potential for the development of late complications such as delayed onset of CAVB, which had been recognized as a unique problem for device closure of VSD, ${ }^{8,15}$ remained unanswered.

In our study, 61 patients with the diagnosis of perimembranous VSD were enrolled for perventricular device closure and 57 patients eventually had successful closure of the defects with devices without mortality or major morbidity. The median duration of follow-up was 22 months, with some patients being followed up for more than 2 years. Our study thus presents a broader experience with more information in a larger cohort with longer follow-ups than any of the previously published data. Four patients in the cohort had unsuccessful perventricular VSD closure. The independent variables mean VSD diameter, device diameter, and subaortic rim were included in the multivariable analysis. The multiple logistic regression analysis showed that subaortic rim was associated with failure of device closure $(\mathrm{OR}=21.471 ; 95 \% \mathrm{CI} 1.188-387.929 ; P=.038)$. The $95 \%$ CI of OR was so wide that it was not completely reliable, but the subaortic rim might serve as a potential predictor for failure of device closure; a smaller subaortic rim would cause more possibility of failure of device closure.

The occurrence of cAVB is the most serious complications related to perventricular device closure. The rate of cAVB caused by surgical repair was reported as $1.1 \%,{ }^{16} 0 \%$ to $5.7 \%$ in percutaneous transcatheter approaches, ${ }^{17-22}$ and specifically $4.5 \%$ in children. ${ }^{15}$ The occurrence rate of cAVB in our cohort was $3.3 \%$. In the second patient, cAVB developed as a late complication
7 months after device closure. His rhythm converted to sinus rhythm after 4 weeks of treatment with dexamethasone, and he remained in stable sinus rhythm for 14 months after recovery. Longer-term follow-up on this patient is essential, because recurrence of cAVB several months after conversion to sinus rhythm with percutaneous device closure has been documented. ${ }^{22}$ No clear causative mechanism has been postulated. In our study, univariate analysis did not find any variable that was associated with the occurrence of cAVB. Although the occurrence of cAVB in percutaneous device closure was significantly associated with age, ${ }^{22}$ it appears that perventricular device closure is safer in young children than is the percutaneous approach. In the case of the percutaneous approach, the catheter must go through the tricuspid valve. This results in the unavoidable "frictional rubbing" with the atrioventricular node and the conduction system, as proposed by Carminati and associates ${ }^{23}$ when reporting on the occurrence of cAVB in 4 patients with muscular VSDs. It is possible that the device may cause an initial inflammatory response with subsequent scar formation within the conduction tissue. During the perventricular approach, the delivering sheath perventricularly approaches the plane of the defect at a perpendicular angle. This angle avoids frequent frictional rubbing with the atrioventricular node and the septal submarginal atrioventricular conduction system and the subsequent inflammatory response and fibrosis.

According to published reports, the effect of steroid therapy is controversial: it may be useful for immediate onset of cAVB after device closure, but it is unlikely to be useful for delayed onset of cAVB. ${ }^{22}$ However, our second patient in whom cAVB developed 7 months later did convert to sinus rhythm with steroid therapy. One possible explanation is that the patient came back to the hospital immediately after the onset of cAVB, while the conduction system was recently affected by the device-related inflammatory response or scar formation. We believe that steroids should be tried first for a period of several weeks for either immediate or delayed onset of cAVB before more drastic means are considered.

No AR was noticed in the patients with successful perventricular device closure during the follow-up period. Two patients in whom AR occurred during the procedure were converted to open repair immediately. Selection of the occlusion device might be pivotal in patients with a subaortic rim less than $2 \mathrm{~mm}$. If the patient has a subaortic rim of

TABLE 3. Data for 4 patients converted to surgical repair

\begin{tabular}{|c|c|c|c|c|c|c|c|}
\hline No. & Gender & Age (y) & Weight (kg) & SAR & Mean diameter of VSD $(\mathbf{m m})$ & Device last tried & Complication \\
\hline 1 & $\mathrm{~F}$ & 3.5 & 11 & $\mathrm{SAR}=1 \mathrm{~mm}$ & 7 & $9 \mathrm{~mm}$, eccentric $(0 \mathrm{~mm})^{*}$ & $\mathrm{AR}$ \\
\hline 2 & M & 3 & 15 & $\mathrm{SAR}=1.5 \mathrm{~mm}$ & 8.5 & $10 \mathrm{~mm}$, eccentric $(0 \mathrm{~mm})$ & $\begin{array}{l}\text { Residual shunt, } \\
\text { width }>2 \mathrm{~mm}\end{array}$ \\
\hline 3 & M & 3 & 18 & $\mathrm{SAR}<1 \mathrm{~mm}$ & 8 & $10 \mathrm{~mm}$, eccentric $(0 \mathrm{~mm})$ & $\mathrm{AR}$ \\
\hline 4 & M & 3 & 10 & $\mathrm{SAR}>2 \mathrm{~mm}$ & 5 & $7 \mathrm{~mm}$, concentric $(2 \mathrm{~mm})$ & $\mathrm{cAVB}$ \\
\hline
\end{tabular}

$F$, Female; $M$, male; $V S D$, ventricular septal defect; $S A R$, subaortic rim; $A R$, aortic regurgitation; $c A V B$ : complete atrioventricular block. *Eccentric $(0 \mathrm{~mm}) \mathrm{means}$ an eccentric device with a least $0 \mathrm{~mm}$ flange on the left ventricular disc. 
TABLE 4. Complications

\begin{tabular}{|c|c|c|c|c|c|}
\hline \multirow[b]{2}{*}{ Category } & \multirow[b]{2}{*}{ Before closure $(n=61)$} & \multicolumn{4}{|c|}{ After closure } \\
\hline & & In OR $(n=61)$ & Discharge $(n=61)$ & After 6 mo $(n=61)$ & After $12 \mathrm{mo}(\mathrm{n}=56)$ \\
\hline Residual shunt & N/A & $4(6.6 \%)$ & $2(3.3 \%)$ & $0(0 \%)$ & $0(0 \%)$ \\
\hline $\mathrm{AR}$ & $0(0 \%)$ & $2(3.3 \%)^{*}$ & $0(0 \%)$ & $0(0 \%)$ & $0(0 \%)$ \\
\hline cAVB & $0(0 \%)$ & $1(1.6 \%)^{*}$ & $0(0 \%)$ & $0(0 \%)$ & $1(1.8 \%) \dagger$ \\
\hline \multicolumn{6}{|l|}{$\mathrm{TR}$} \\
\hline Pre-existent & $15(24.6 \%)$ & $11(18.0 \%)$ & $10(16.4 \%)$ & $6(9.8 \%)$ & $6(10.7 \%)$ \\
\hline Closure & N/A & $8(13.1 \%)$ & $5(8.2 \%)$ & $4(6.6 \%)$ & $4(7.1 \%)$ \\
\hline \multicolumn{6}{|l|}{ induced } \\
\hline MR & $3(4.9 \%)$ & $2(3.3 \%)$ & $2(3.3 \%)$ & $1(1.6 \%)$ & $1(1.8 \%)$ \\
\hline IRBBB & $0(0 \%)$ & $5(8.2 \%)$ & $3(4.9 \%)$ & $3(4.9 \%)$ & $3(5.4 \%)$ \\
\hline
\end{tabular}

$O R$, Operating room; $N / A$, not available; $A R$, aortic regurgitation; $c A V B$, complete atrioventricular block; $T R$, Tricuspid regurgitation; $M R$, Mitral regurgitation; $I R B B B$, incomplete right bundle branch block. *The patients were converted to conventional open cardiac surgery. $\dagger$ One patient developed cAVB 7 month after closure had recovered sinus rhythm.

only 1 to $2 \mathrm{~mm}$ wide, an eccentric occluder with a 0.5 -mm or less flange on the LV disc was recommended. If the subaortic rim is less than $1 \mathrm{~mm}$ wide, our first choice would be an eccentric occluder without a flange on the LV disc facing the aortic valve. During the procedure, the surgeon should be very cautious not to injure the aortic valve when manipulating the guide wires or catheters through the defect. Patients with a subaortic rim of $2 \mathrm{~mm}$ or less should be followed up for a sufficiently long period of time to assess the effect of the devices on the valve function.

In the postoperative period, all pre-existing tricuspid regurgitations diminished or remained unchanged, but new tricuspid regurgitation graded as trivial occurred in 8 patients. We speculated that this might be caused by the distortion of the subvalvular apparatus by the newly implanted device. The surgeon should observe the movement of the valves and evaluate the valve regurgitation (if any) with TEE before deciding to release the device, redeploy the device, or remanipulate the guide wire. If the situation cannot be rectified after several attempts, then the procedure should be converted to surgical repair.

Nowadays, several minimally invasive surgical approaches for heart surgery have been proposed, including right submammary minithoractomy ${ }^{24}$ and inferior partial sternotomy ${ }^{25}$; cosmesis is getting more important for the young patients. Besides the cosmetic advantages, perventricular device closure of perimembranous VSD is technically simple and, at the same time, avoids the undesirable adverse effects of prolonged fluoroscopy and trauma to the small access vessels in young children, as in the case of percutaneous intervention. It also completely avoids the deleterious side effects of $\mathrm{CPB}$, as in the case of conventional surgical repair. Inasmuch as perventricular device closure is performed under the continuous monitoring of TEE, instant "online" feedback with respect to significant residual shunt and procedure-related new tricuspid insufficiency is available for immediate rectification. In our cohort, residual shunt was detected in 4 patients, and in 1 of them the procedure was converted to surgical repair. Residual shunts in the other 3 patients were graded as trivial $(<1 \mathrm{~mm}$ color jet width), and because the devices were determined to be in good position, we elected not to convert to surgical repair after confirming their stability. All 3 residual shunts subsequently disappeared within 6 months.

\section{Limitations}

There are several limitations to this study. First, angiography not performed in any of the patients; therefore, no hemodynamic data were available. Second, the technique of perventricular device closure of perimembranous VSD appeared to be safe with minimal late occurrence of arrhythmia and valve dysfunction in the early and midterm follow-up, but whether these good outcomes will persist in the long run remains to be determined.

\section{CONCLUSIONS}

Our results suggest that perventricular device closure of perimembranous VSD is a safe, efficacious, and relatively simple treatment modality that eliminates the known adverse side effects of the currently mainstream approaches, namely, open surgical repair. Our midterm follow-up data also suggest that this approach is enduring with minimal late complications up to 16 months and, in some instances, even longer.

\section{References}

1. Elliott MJ. Recent advances in paediatric cardiopulmonary bypass. Perfusion. 1999;14:237-46

2. Limperopoulos C, Majnemer A, Shevell MI, Rohlicek C, Rosenblatt B, Tchervenkov C, et al. Predictors of developmental disabilities after open-heart surgery in young children with congenital heart defects. J Pediatr. 2002;141:51-8.

3. Bellinger DC, Wypij D, duPlessis AJ, Rappaport LA, Jonas RA, Wernovsky G et al. Neurodevelopmental status at eight years in children with dextrotransposition of the great arteries: the Boston Circulatory Arrest Trial. J Thorac Cardiovasc Surg. 2003;126:1385-96.

4. Gessler P, Schmitt B, Prètre R, Latal B. Inflammatory response and neurodevelopmental outcome after open-heart surgery in children. Pediatr Cardiol. 2009;30: 301-5.

5. Knauth AL, Lock JE, Perry SB, McElhinney DB, Gauvreau K, Landzberg MJ, et al. Transcatheter device closure of congenital and postoperative residual ventricular septal defects. Circulation. 2004;110:501-7.

6. Pedra CA, Pedra SR, Esteves CA, Pontes SC Jr, Braga SL, Arrieta SR, et al. Percutaneous closure of perimembranous ventricular septal defects with the 
Amplatzer device: technical and morphological considerations. Catheter Cardiovasc Interv. 2004;61:403-10.

7. Bacha EA, Cao QL, Starr JP, Waight D, Ebeid MR, Hijazi ZM. Perventricular device closure of muscular ventricular septal defects on the beating heart: technique and results. J Thorac Cardiovasc Surg. 2003;126:1718-23.

8. Amin Z, Berry JM, Foker JE, Rocchini AP, Bass JL. Intraoperative closure of muscular ventricular septal defect in a canine model and application of the technique in a baby. J Thorac Cardiovasc Surg. 1998;115:1374-6.

9. Zeng XJ, Sun SQ, Chen XF, Ma XJ, Luo YH, Lim YP, et al. Device closure of perimembranous ventricular septal defects with a minimally invasive technique in 12 patients. Ann Thorac Surg. 2008;85:192-4.

10. Li F, Chen M, Qiu Z, Lu J, Wu W. A new minimally invasive technique to occlude ventricular septal defect using an occluder device. Ann Thorac Surg. 2008;85: 1067-71.

11. Gan C, An Q, Lin K, Tang H, Lui RC, Tao K, et al. Perventricular device closure of ventricular septal defects: six months results in 30 young children. Ann Thorac Surg. 2008;86:142-6.

12. Quansheng X, Silin P, Zhongyun Z, Youbao R, Shengde L, Qian C, et al. Minimally invasive perventricular device closure of an isolated perimembranous ventricular septal defect with a newly designed delivery system: preliminary experience. J Thorac Cardiovasc Surg. 2009;137:556-9.

13. Butera G, Massimo C, Mario C. Late complete atriovenous block after percutaneous closure of a perimembranous ventricular septal defect. Catheter Cardiovasc Interv. 2006;67:938-41.

14. Okubo M, Benson LN, Nykanen D, Azakie A, Van Arsdell G, Coles J, et al. Outcomes of intraoperative device closure of muscular ventricular septal defects. Ann Thorac Surg. 2001;72:416-23.

15. Butera G, Carminati M, Chessa M, Piazza L, Abella R, Negura DG, et al. Percutaneous closure of ventricular septal defects in children aged $<12$ : early and mid-term results. Eur Heart J. 2006;27:2889-95.
16. Tucker EM, Pyles LA, Bass JL, Moller JH. Permanent pacemaker for atrioventricular conduction block after operative repair of perimembranous ventricular septal defect. J Am Coll Cardiol. 2007;50:1196-200.

17. Bass JL, Kalra GS, Arora R, Masura J, Gavora P, Thanopoulos BD, et al. Initial human experience with the Amplatzer perimembranous ventricular septal occluder device. Catheter Cardiovasc Interv. 2003;58:238-45.

18. Masura J, Gao W, Gavora P, Sun K, Zhou AQ, Jiang S, et al. Percutaneous closure of perimembranous ventricular septal defects with the eccentric Amplatzer device: multicenter follow-up study. Pediatr Cardiol. 2005;26:216-9.

19. Holzer R, de Giovanni J, Walsh KP, Tometzki A, Goh T, Hakim F, et al. Transcatheter closure of perimembranous ventricular septal defects using the Amplatzer membranous VSD occluder: immediate and midterm results of an international registry. Catheter Cardiovasc Interv. 2006;68:620-8.

20. Carminati M, Butera G, Chessa M, Drago M, Negura D, Piazza L. Transcatheter closure of congenital ventricular septal defect with Amplatzer septal occluders. Am J Cardiol. 2005;96:52L-8.

21. Butera G, Chessa M, Carminati M. Percutaneous closure of ventricular septal defects. Cardiol Young. 2007;17:243-53.

22. Butera G, Carminati M, Chessa M, Piazza L, Micheletti A, Negura DG, et al. Transcatheter closure of perimembranous ventricular septal defects: early and long-term results. J Am Coll Cardiol. 2007;50:1189-95.

23. Carminati M, Butera G, Chessa M, De Giovanni J, Fisher G, Gewillig M, et al. Transcatheter closure of congenital ventricular septal defects: results of the European Registry. Eur Heart J. 2007;28:2361-8.

24. Mishaly D, Ghosh P, Preisman S. Minimally invasive congenital cardiac surgery through right anterior minithoracotomy approach. Ann Thorac Surg. 2008;85: $831-5$.

25. Hagl C, Stock U, Haverich A, Steinhoff G. Evaluation of different minimally invasive techniques in pediatric cardiac surgery: is a full sternotomy always a necessity? Chest. 2001;119:622-7. 